\title{
A Comparative Structural Equation Modeling Investigation of the Relationships among Teaching, Cognitive and Social Presence
}

\author{
Kadir Kozan \\ Purdue University
}

\begin{abstract}
The present study investigated the relationships among teaching, cognitive, and social presence through several structural equation models to see which model would better fit the data. To this end, the present study employed and compared several different structural equation models because different models could fit the data equally well. Among the models compared, the results indicated that the model with cognitive presence as a full mediator and the model with social presence as a partial mediator could achieve an equally satisfactory data fit. This conclusion may depend on the level of the presences: The present results indicated a statistically higher level of teaching presence than cognitive and social presence as well as a statistically higher level of cognitive presence compared to social presence. The results further suggested that teaching presence could either have a direct or indirect relationship with cognitive presence thereby increasing it without or with social presence as a mediator between teaching and cognitive presence. The results further suggested that teaching presence efforts spent on increasing cognitive presence can function directly, which may also promote social presence, and indirectly through social presence. Further research comparing different possible structural equation models of the relationships among the presences in different learning contexts is warranted.
\end{abstract}

\section{Introduction}

Online learning or education theories are important for evaluating online higher education (Kozan \& Richardson, 2014a). In this regard, Boston, Diaz, Gibson, Ice, Richardson, \& Swan (2009) claimed that the Community of Inquiry (CoI) framework (Garrison, 2011, 2013; Garrison \& Akyol, 2013a, b; Garrison $\&$ Arbaugh, 2007) may serve formative evaluation attempts focusing on the quality of online education and learner retention. Focusing primarily on the learning process (Akyol et al., 2009; Swan Garrison, \& Richardson, 2009), the CoI framework builds on teaching, social, and cognitive presence, and suggests 
that the presences be at a certain level to encourage learning. Teaching presence is "the design, facilitation, and direction of cognitive and social processes for the purpose of realizing personally meaningful and educationally worthwhile learning outcomes." (Anderson, Rourke, Garrison, and Archer, 2001, p. 5). Further, according to Garrison (2009), social presence is "the ability of participants to identify with the community (e.g., course of study), communicate purposefully in a trusting environment, and develop interpersonal relationships by way of projecting their individual personalities" (p. 352). Finally, cognitive presence refers to extracting meaning from a learning experience by continuously reflecting and communicating (Garrison, Anderson, \& Archer, 2000, 2001).

The CoI framework assumes strong interconnections among the three presences the validity of which has been addressed before (e.g., Kozan, 2016). After all, it is assumed that educational or learning experiences occur in the common area or intersection shared by the presences (e.g., Arbaugh et al., 2008). Likewise, according to Diaz, Swan, Ice, and Kupczynski (2010), the CoI framework has a strong tendency to position "learning processes in the interaction of all three presences" (p. 23). Despite the relative lack of relevant research highlighted earlier (e.g., Garrison \& Arbaugh, 2007), all these suggest that the interrelationships between and among the presences are worth investigation in order to fully understand how they affect learning experiences. Specifically, more insights gained into these interrelationships may inform us more about the nature of the CoI framework that is dynamic and process-focused depending on the learners and learning context (Kozan \& Richardson, 2014a). Experimental application of theory would enhance and let us make the most out of theoretical insights (Kozan \& Richardson, 2014a). Consequently, going beyond a one-model research design, the present study aims at furthering our understanding of the causal interrelationships between and among the presences by statistically comparing different possible models of these interrelationships.

\section{Literature Review}

Garrison and Arbaugh (2007) pointed out that we need "to better understand the interdependence of the three elements" (p. 166) of the CoI Framework and claimed that earlier research mainly focused on one presence at a time instead of approaching the framework holistically with attention to how the presences interrelate. Similarly, according to Akyol and Garrison (2008), the process-oriented nature of the CoI framework emphasizes the "need to study the dynamics of its constituting elements" (Akyol \& Garrison, 2008, p. 4) which fully aligns with its focus on the interaction of the presences (Diaz et al., 2010). The existing research on the interrelationships between and among the presences is basically either correlational or causal.

To begin with, in their 2008 study, Akyol and Garrison conducted correlational analyses based on the data collected through the CoI survey (2014). Their results revealed only one significant and large relationship which was between teaching presence and cognitive presence $\left(r_{\mathrm{s}}=.779\right)$. This is not in line with the assumption of the CoI framework that there should be interactions among the presences. Given the small sample size employed in the study $(N=15)$, the results may not be conclusive. However, the size and statistical significance of the relationship between teaching presence and cognitive presence despite the small sample size should be acknowledged here.

$\mathrm{Ke}$ (2010) also employed regression and correlation analyses to investigate the interconnections among teaching presence, social presence, and cognitive presence. Ke (2010, p. 817) defined each as follows:

- teaching presence is the "pre-determined or fluid" characteristics of online course content design and online discussion design as based on "grade proportion, purpose, participation unit, and communication format"; 
- social presence is the "responses to Classroom Community Scale" noted by Rovai (2002) and "the amount of social interaction units";

- cognitive presence is "the degree of learning satisfaction, the degree of self-perceived deep \& surface learning, and the amount of knowledge-constructive interaction units".

Ke (2010) found that content and discussion design can significantly predict knowledge-constructive interaction units and social interaction in addition to small to large correlations between different components of each presence. For instance, there was a significant but small relationship between participation unit and the number of knowledge-constructive units $(r=.27)$ while there was a significant and large relationship between learning satisfaction and community sense $(r=.71)$. Using the same line of logic and employing standard multiple regression, Archibald (2010) studied whether teaching and social presence could predict cognitive presence. This conceptualization concurs with the tradition to regard cognitive presence as more like a result of the learning process compared to the other two presences. The researcher found that together, teaching and social presence could significantly predict cognitive presence, noting that the contribution of social presence to the prediction of cognitive presence appears to be larger.

Using a similar correlational analysis methodology based on the data from a quantitative content analyses of online discussions employed in two fully online business management courses, Shea et al. (2010) reported a significantly large interaction $(r=.97)$ between high amount of instructor teaching presence and student social presence excluding the beginning of an online course. Likewise, there was a significantly large relationship $(r=.98)$ between high instructor social presence and student social presence. These numbers should be approached carefully since they may refer to multicollinearity or singularity between the variables suggesting that the variables may not be entirely separable.

Recently, Kozan and Richardson (2014a) conducted partial correlation analyses in addition to bivariate correlations between and among the presences using the CoI survey (2014). Partial correlations determined the relationship between any of the two presences while controlling for the third one. All bivariate correlations turned out to be significantly large and positive. Partial correlations suggested that it was only cognitive presence that has an impact on the relationship between teaching and social presence. On the other hand, the relationship between teaching and cognitive presence, and the one between cognitive and social presence was independent of the effect of the third presence. In other words, only cognitive presence functioned as a mediator between teaching and social presence.

As for the causal relationships between and among the presences, two studies appear to stand out: A structural equation modeling study by Shea and Bidjerano (2009) implemented the CoI survey (2014) using a large sample $(n=2159)$ in an online learning environment. Results yielded significant direct relationships between teaching and social presence, and between social and cognitive presence as well as those between age and teaching presence, and gender and teaching presence. Accordingly, the researchers pointed to a significant relationship between teaching and cognitive presence with social presence having a partial mediator role. Another study conducted by Garrison, Cleveland-Innes and Fung (2010) tested the causal relationships between and among the presences running a structural equation modeling analysis. The results were in line with Shea and Bidjerano (2009) in that there was a direct significant relationship between teaching and social presence in addition to those between teaching and cognitive presence, and between social presence and cognitive presence supporting the idea of social presence as a partial mediator.

Most of the research above had a tendency to treat cognitive presence as an outcome variable while trying to establish the relationships between and among the presences (e.g., Archibald, 2010; Ke, 2010; Shea \& Bidjerano, 2009; Garrison et al., 2010). Furthermore, 
Bollen and Pearl (2013) claimed that causal assumptions of the researchers determine the structural equation models, which implies that there might be other alternative models that can fit research data (Tomarken \& Waller, 2005). Consequently, the somewhat varied results obtained regarding the interrelationships between and among the presences indicated the potential value of comparing different models of causal relationships between and among the presences to determine whether these models are statistically different from each other. In other words, it is reasonable to check which of the researchbased causal models used to evaluate the interrelationships between and among the presences is a better statistical fit for the current data. For this reason, the current study employed structural equation modeling analyses aimed at addressing the following complementary questions: How do the possible structural equation models of the interrelationships between and among the presences informed by earlier research and theoretical insights compare with each other? Are there any statistical differences between them in terms of fitting the data set used in the present study?

\section{Research Setting}

\section{Method}

Data collection occurred in a fully online Learning, Design, and Technology Master of Science (MS) Program at a large Midwestern U.S. public university. Students from eleven online graduate courses ( 3 credits each) contributed to the data collection. These graduate level courses were a mix of required and elective courses that focused on foundational subject area content. These courses included miscellaneous projects and assignments that are typical of graduate courses. These courses were delivered through the university's online learning management system.

\section{Participants}

Participants were graduate students, most of whom were online MS graduate students (320; 94.7 $\%$ ) in learning, design and technology. This majority was not affiliated with the university campus and worked in positions related to instructional design or human performance which stood to benefit from their MS degree. Of the participants affiliated with the university, nine $(2.7 \%)$ were on-campus learning, design and technology MS students; seven (2.1\%) were learning, design and technology doctoral students taking MS-level online courses; and two $(.5 \%)$ were graduate students from other programs. As for previous experiences with online learning, $38(11.2 \%)$ participants reported that they had never taken an online course prior to data collection; six $(1.8 \%)$ had taken one online course; $84(24.9 \%)$ had taken two to four online courses; and $210(62.1 \%)$ had previously taken five or more online courses. After eliminating duplicate cases, - one of the duplicate cases was randomly preserved and used for data analysis - , and checking assumptions, there was a final total of 338 participants or cases for use in this study.

\section{Instrument}

Arbaugh et al. (2008) invented the CoI survey (2014), a Likert-type questionnaire consisting of 34 items that measure presences in online learning. The CoI survey (2014) used in this study was designed to measure teaching presence, social presence, and cognitive presence within the same survey, with 13 items related to teaching presence, nine items related to social presence, and 12 items related to cognitive presence. Existing research in the field established the validity and the reliability of the CoI survey (2014) or of a slightly adapted version (e.g., Arbaugh et al., 2008; Diaz et al., 2010; Kozan \& Richardson, 2014b; Swan et al., 2008).

An adapted version (see Appendix) of the original CoI survey (2014) ranging from strongly disagree to strongly agree was employed in the present study. The scale range strongly disagree strongly agree used codes as $1-5$ for data analysis purposes even though the numbers were not shown on the online survey used. In this study, replacements or modifications were made to two original survey items. Original survey item number 12 (The instructor provided feedback that helped me understand my 
strengths and weaknesses relative to the course's goals and objectives) was replaced with The instructor provided feedback that helped me understand my strengths and weaknesses taken from the Community of Inquiry Survey Instrument (draft v14) (n.d.) on The Community of Inquiry website, and wording in item number 28 (Online discussions were valuable in helping me appreciate different perspectives), was modified ( Discussing course content with my classmates was valuable in helping me appreciate different perspectives: J. Richardson, personal communication, n.d.). Cronbach's Alpha values indicated high internal consistency or reliability indices for teaching presence (.956); social presence (.914); and cognitive presence (.943) based on the survey. Similarly, there was a high internal consistency of the whole survey (.968).

\section{Procedures}

The actual version of the CoI survey used to collected data was designed using Qualtrics online survey platform. As a part of the course evaluation efforts, the link to the survey was distributed to participants towards the end of the semester via the university's online learning management system. Data collection continued during four consecutive eight-week academic sessions.

Data analysis began with data screening and preliminary analyses focusing on out-of-range scores, missing data, univariate and multivariate outliers, normal distribution, multicollinearity or singularity, and linearity. The 46 out-of-range data points were deemed erroneous and were subsequently eliminated from the study, which turned them into missing data. Less than $5 \%$ of the data points from each variable were missing. Because substituting less than $5 \%$ missing data via any procedure produces similar results (Tabachnick \& Fidell, 2013), the missing data points for each item were replaced with the mean of their fellow presence items. This is further legitimized by the high internal reliability indices of each part of the CoI survey including the missing data (teaching presence: .962; social presence: .908; cognitive presence: .941).

A check of univariate and multivariate cases led to the deletion of 59 cases, which resulted in a final total of 338 participants. None of the 34 items of the CoI survey scores followed a normal distribution thereby being negatively skewed. Garrison (2012) highlighted and criticized accepting all learning contexts investigated as real learning communities without enough insights in earlier CoI research. In the same line of logic, Matthews, Bogle, Boles, Day, and Swan (2013) suggested that CoI survey items with ratings "less than 3.75 , or slightly less than "agree" (4)" on average in a 1-5 scale would be problematic (p. 493). The mean ratings of the survey items in this study ranged from $4.26(S D=$ $.735)$ to $4.66(S D=.520)$, which is high, but the negative skewness observed appears to be normal and can even be regarded as necessary to achieve a highly effective learning community. Further, Field (2009) pointed out that there is a lack of universal agreement on the necessity of transforming variables, which can lead to its own problems. Similarly, Tabachnick and Fidell (2013) stated that transformations "are not universally recommended" (p. 86) due to the potential difficulty of interpretation. Accordingly, no transformations were used on any of the survey items in this study, leaving them in their original state for analysis. Finally, a correlation analysis with a threshold of .90 or above (Tabachnick \& Fidell, 2013) revealed neither multicollinearity nor singularity among the survey items. Finally, a confirmatory factor analysis for checking the measurement model and a structural equation modeling analysis for checking relationships between and among the presences were conducted to answer the research questions using Lisrel 8.80 (Jöreskog \& Sörbom, 2007).

\section{Results and Discussion}

\section{Descriptive Statistics}

Table 1 showcases the descriptive statistics for each presence as a variable. Teaching presence was measured through the first 13 items of the CoI survey, social presence was measured through the next 
9 items, and cognitive presence through last 12 items. The numbers in parentheses indicate frequencies or the number of participants who reported a particular number in Table 1.

Table 1.

Descriptive statistics $(N=338)$

\begin{tabular}{lcccccc}
\hline & $\begin{array}{c}\text { Possible } \\
\text { minimum }\end{array}$ & Minimum & $\begin{array}{c}\text { Possible } \\
\text { Maximum }\end{array}$ & Maximum & Mean & $S D$ \\
\hline TP & 13 & $36(1)$ & 65 & $65(109)$ & 58.86 & 7.03 \\
\hline SP & 9 & $27(1)$ & 45 & $45(82)$ & 40.21 & 4.30 \\
\hline CP & 12 & $36(1)$ & 60 & $60(90)$ & 54 & 5.60 \\
\hline Total & 34 & $104(1)$ & 170 & $170(53)$ & 153 & 15 \\
\hline
\end{tabular}

Note. $\mathrm{TP}=$ Teaching presence. $\mathrm{SP}=$ Social presence. $\mathrm{CP}=$ Cognitive presence.

It is important to note that the means of each presence and the total presence are quite close to possible maximum scores (Table 1). This highlights that the research context of this study housed an effective community of inquiry on average based on participants' perceptions. Moreover, Matthews et al.'s (2013) guidelines for a slightly smaller rating than 4 suggests a composite mean of 52 for teaching presence, 36 for social presence, and 48 for cognitive presence, all of which are less than the means for each presence shown in Table 1. Interestingly, only one of the participants reported the minimum presence and total presence ratings while maximum ratings were reported by at least 53 participants.

It should be noted here that the means in Table 1 were calculated across all participants, which might include individual participant ratings that would be less than the result of the calculation formula of number of items*4 or slightly less than 4 . Eliminating such individual cases is possible; however, it would be quite strict, making the data set much more negatively skewed (Kozan \& Richardson, 2014b). Calculating the average for all participants also may help to control some of the ratings that reported as too high or too low in a given sample. The average ratings of individual items ranged from $4.42(S D=$ $.816)$ to $4.66(S D=.520)$ for teaching presence, from $4.26(S D=.735)$ to $4.60(S D=.534)$ for social presence, and from $4.41(S D=.626)$ to $4.63(S D=.520)$ for cognitive presence. All these numbers as well as the negatively skewed distribution of the data for all survey items strongly suggest that participants perceived quite a high level of presence.

\section{The Hypothesized Model and Correlations among the Presences}

Bivariate and partial correlation analyses were run to check the relationships among the presences, and to set the stage for the hypothesized structural equation model in this study for comparison with others, including the ones suggested by Garrison et al. (2010), and Shea and Bidjerano (2009). Table 2 shows the correlations between and among the presences.

Table 2.

Bivariate and partial correlations among the presence types $(N=338)$

\begin{tabular}{lccccccccc}
\hline & & TP & \multicolumn{3}{c}{ SP } & \multicolumn{3}{c}{ CP } \\
\hline Presence & $r$ & $r_{\mathrm{s}}$ & $p r$ & $r$ & $r_{\mathrm{s}}$ & $p r$ & $r$ & $r_{\mathrm{s}}$ & $p r$ \\
\hline TP & - & - & - & $.559^{*}$ & $.595^{*}$ & $.090^{\mathrm{a}}$ & $.703^{*}$ & $.726^{*}$ & $.519^{*}$ \\
\hline SP & & & & - & - & - & $.734^{*}$ & $.752^{*}$ & $.578^{*}$ \\
\hline $\mathrm{CP}$ & & & & & & & - & - & - \\
\hline
\end{tabular}

Note. ${ }^{a} p=.097 .{ }^{*} p<.001 . \mathrm{TP}=$ Teaching presence.

$\mathrm{SP}=$ Social presence. $\mathrm{CP}=$ Cognitive presence. 
These results align fully with Kozan and Richardson's (2014a) finding that of these three presences, cognitive presence likely functions as a mediator between teaching and social presence. While controlling for cognitive presence, the relationship between teaching and social presence disappears as indicated by the partial correlation between teaching and social presence $(p r=.090, n=338, p=.097)$. On the other hand, while controlling for teaching presence or social presence, the relationships between social and cognitive presence, and between teaching and cognitive presence, decrease in magnitude and stay significantly moderate. This might further suggest that teaching presence and social presence function more like a moderator within a community of inquiry.

Little, Cunningham, and Shahar (2002) stated that parceling items is warranted under the following conditions: when parceling occurs on an unidimensional scale; when the research focus is on the relationships among the constructs; and when "the goal of an investigator is to model effects of a latent variable at a given level of generality" (p. 171). In this study, each section of the CoI survey was unidimensional (i.e., measuring each presence separately) and consisted of unidimensional subparts; the research purpose was to focus on the relationships among the three presences; and the subparts of each CoI survey section combined successfully under the umbrella of each presence. Therefore, the survey items were parceled into groups as shown in Figure 3. Specifically, each dimension of the presences (i.e., teaching presence: design and organization [4 items], facilitation [6 items], direct instruction [3 items]; social presence: affective expression [3 items], open communication [3 items], group cohesion [3 items]; cognitive presence: triggering event [3 items], exploration [3 items], integration [3 items], resolution [3 items], were used as one single item or parcel in the new model.

The Cronbach's Alpha values were as follows: .899 for design and organization, .935 for facilitation, .793 for direct instruction, .761 for affective expression, .930 for open communication, .815 for group cohesion, .861 for triggering event, .830 for exploration, .885 for integration, and .862 for resolution. According to Hall, Snell, and Foust (1999):

Item parcels differ from subscale or scale scores in that the entire set of item parcels reflects a single primary factor dimension, or latent construct, whereas a set of subscale or scale scores reflects several separable (though generally closely related) latent constructs. (p. 234).

The subscales or sections of the CoI survey aimed at measuring each presence type (i.e., teaching, social and cognitive presence) while the subparts of these subscales measured different dimensions of each presence. Therefore, parceling CoI survey items per each dimension of survey sections appeared reasonable since, when combined, they point to one single factor (teaching, social or cognitive presence in this study), which seems to align with Hall et al.'s (1999) point above. This way of parceling also seems to have an "a priori structure that has a previous theoretical and/or empirical basis" such that parceling decision may depend on "a theoretical or empirical rationale developed by the researcher" (Hall et al., 1999, p. 236) as well.

Little et al. (2002) defined a parcel as "the sum (or average) of two or more items" (p. 152). In this study, parcels referred to the sum of relevant survey items grouped into each dimension of the CoI survey sections. Accordingly, a structural equation model in which teaching presence has a direct link to cognitive presence, cognitive presence has a direct link to social presence, and teaching presence has an indirect link to social presence was hypothesized to be an alternative for comparison with the final model suggested by Garrison et al. (2010), and Shea and Bidjerano (2009). Figure 1 presents this hypothesized initial model.

\section{Confirmatory Factor Analysis}

Regarding "an analysis of the measurement model" and "the structural relationships among latent constructs", Houghton and Jinkerson (2007) stated that "A two-step process is preferred because it 
ensures that the latent constructs are adequately measured before examining the structural relationships in the model" (p. 49). The researchers also used a confirmatory factor analysis (CFA) to check their measurement model(p. 50). Byrne (1998) stated that when there is theoretical knowledge or "some knowledge of the underlying latent variable structure", a "CFA appropriately is used", which "represents what has been termed a measurement model" (p. 6). For this reason, a CFA was conducted in this study to examine the measurement model as specified by the parceled model seen in Figure 1 prior to testing the relationships among the constructs.

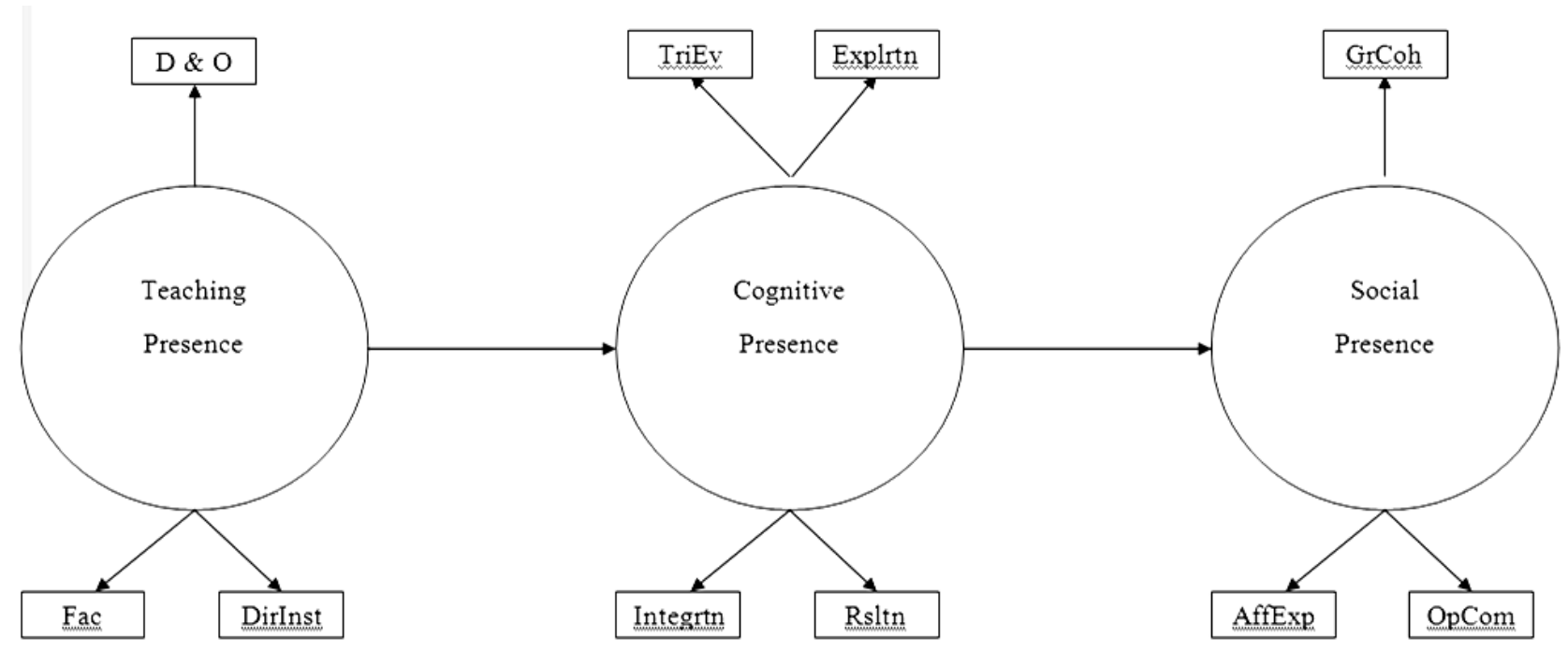

Figure 1. The hypothesized initial model (Model 1). D \& $\mathrm{O}=$ Design and organization. Fac $=$ Facilitation. DirInst $=$ Direct instruction. TriEv $=$ Triggering event. Explrtn $=$ Exploration. Integrtn $=$ Integration. Rsltn $=$ Resolution. GrCoh $=$ Group cohesion. AffExp = Affective expression. OpCom = Open communication .

The results of the CFA pointed to a fairly reasonable fit $\left(\square^{2}[32, \mathrm{~N}=338, p=.00]=92.76\right.$; Goodness of fit index $[\mathrm{GFI}]=0.95$; root mean square error of approximation $[\mathrm{RMSEA}]=0.073$; incremental fit index $[\mathrm{IFI}]=0.99$; comparative fit index $[\mathrm{CFI}]=0.99$; non-normed fit index $[\mathrm{NNFI}]=$ 0.99). Levesque, Stanek, Zuehlke, and Ryan (2004) pinpointed that GFI, CFI, and IFI, which are equal to or higher than 0.90, are generally regarded as acceptable. Levesque et al. (2004) further stated that an RMSEA of 0.05 or smaller is an indication of a very good fit, and a value between 0.08 and 0.05 point to a reasonable fit, while values higher than .10 to a poor fit. All $t$ values bigger than 3.29 in magnitude suggested that factor loadings were significant $(p=.001)$. As a result, respecification of the measurement model was not employed. Because Pearson's correlations $(r)$ were used in data analysis, Table 3 (next page) presents $r$ correlations among the item parcels and the descriptive statistics for the parcels.

\section{Structural Equation Model Analysis on the Hypothesized Model}

The initially hypothesized model as depicted in Figure 1 above characterizes teaching presence as the exogenous variable while describing cognitive presence and social presence as the endogenous variables. It also assumes cognitive presence as a mediator between teaching presence and social presence. This conceptualization has been reproduced below, where the right arrows represents relations between the presences:

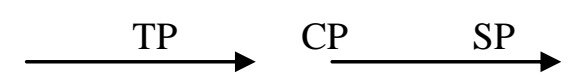

Figure 2. The reproduced hypothetical initial model (Model 1). TP = Teaching presence. $\mathrm{CP}=$ Cognitive presence. $\mathrm{SP}=$ Social presence. 
Table 3.

Descriptive statistics and correlations among the parceled indicators $(N=338)$

\begin{tabular}{|c|c|c|c|c|c|c|c|c|c|c|c|c|}
\hline Indicators & $M$ & $S D$ & 1 & 2 & 3 & 4 & 5 & 6 & 7 & 8 & 9 & 10 \\
\hline 1. DO & 18.45 & 2.08 & - & & & & & & & & & \\
\hline 2. Fclttn & 27.00 & 3.54 & .808 & - & & & & & & & & \\
\hline 3. DI & 13.43 & 1.85 & .787 & .844 & - & & & & & & & \\
\hline 4. TE & 13.32 & 1.71 & .528 & .611 & .586 & - & & & & & & \\
\hline 5. Explrtn & 13.41 & 1.56 & .507 & .594 & .581 & .747 & - & & & & & \\
\hline 6. Intgrtn & 13.50 & 1.60 & .602 & .647 & .665 & .798 & .780 & - & & & & \\
\hline 7. Rsltn & 13.70 & 1.43 & .497 & .581 & .583 & .658 & .623 & .691 & - & & & \\
\hline 8. GC & 13.30 & 1.63 & .410 & .497 & .470 & .606 & .662 & .656 & .592 & - & & \\
\hline 9. $\mathrm{AE}$ & 13.13 & 1.70 & .461 & .545 & .522 & .554 & .640 & .586 & .524 & .694 & - & \\
\hline 10. OC & 13.80 & 1.52 & .408 & .409 & .443 & .478 & .541 & .552 & .568 & .765 & .609 & - \\
\hline
\end{tabular}

Note: All correlations were significant at $p=.01$.

$\mathrm{DO}=$ Design and organization. Fclttn $=$ Facilitation. $\mathrm{DI}=$ Direct instruction.

$\mathrm{TE}=$ Triggering event . Explrtn $=$ Exploration. Intgrtn $=$ Integration.

Rsltn $=$ Resolution $. \mathrm{GC}=$ Group cohesion. $\mathrm{AE}=$ Affective expression .

$\mathrm{OC}=$ Open communication.

A structural equation modeling analysis was employed to test the hypothesized relationships suggested by the model seen in Figure 2. Results revealed that the hypothesized model shows an excellent fit based on GFI $=0.95$, IFI $=0.99, \mathrm{CFI}=0.99$, and NNFI $=0.98$. RMSEA at 0.076, on the other hand, pointed to a reasonable fit. Therefore, it is reasonable to assume that the hypothesized model showed a very good fit, $\square^{2}[33, \mathrm{~N}=338, p=.00]=100.73$. Accordingly, no further modifications were run on the model. Finally, $t$ values for all model specifications were higher than 3.29, thereby being significant at $p<$ .001 . Figure 3 represents the final model with standardized factor loadings and regression coefficients.

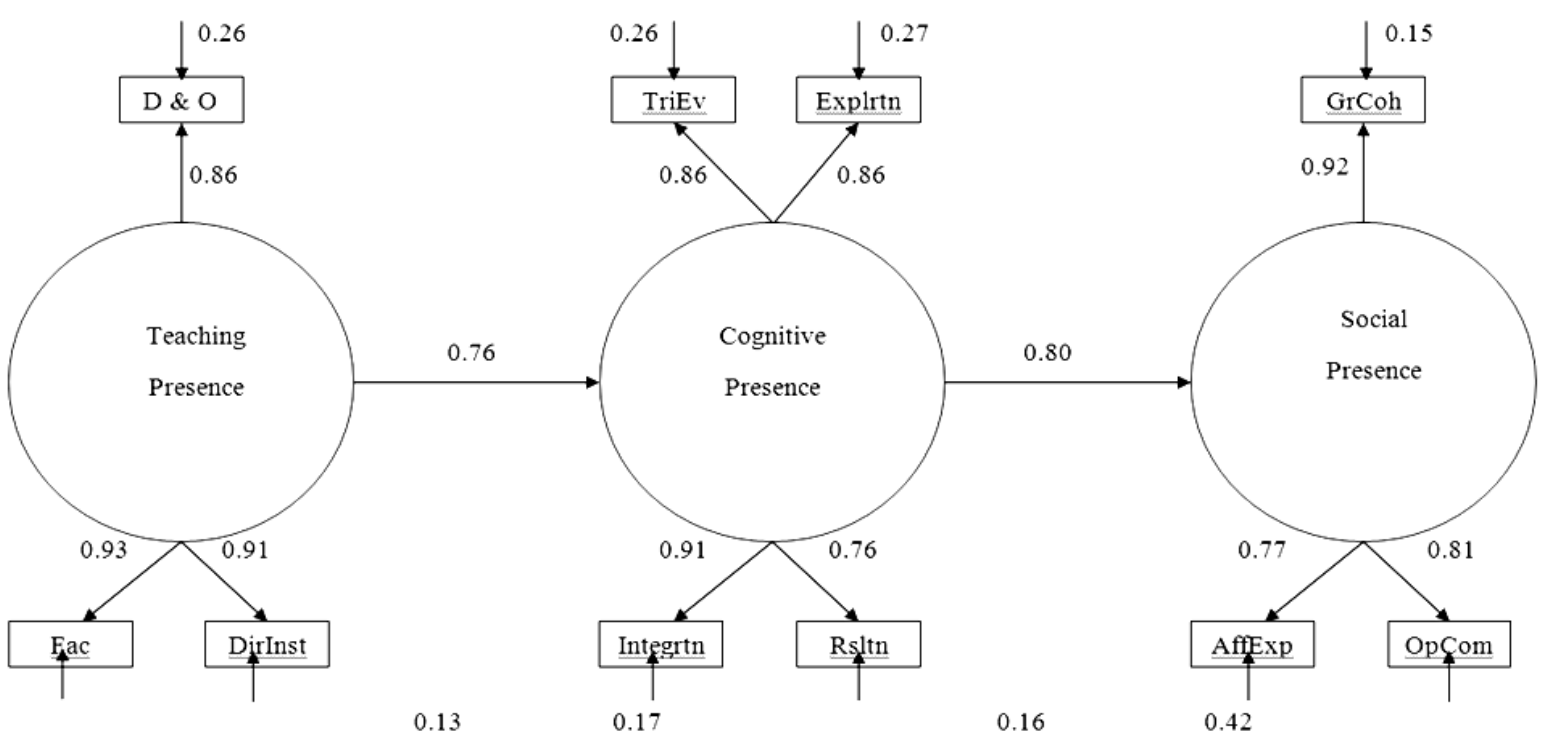

Figure 3. The final model with standardized indices (Model 3). D \& $\mathrm{O}=$ Design and organization. Fac $=$ Facilitation. DirInst $=$ Direct instruction. TriEv $=$ Triggering event. Explrtn $=$ Exploration. Integrtn $=$ Integration. Rsltn $=$ Resolution. GrCoh $=$ Group cohesion. AffExp $=$ Affective expression. OpCom $=$ Open communication. 


\section{Comparison of Structural Equation Models}

To fulfill the purpose of comparing research- and theory-based models of the relationships between and among the presences, some alternative models were run and compared to the final model obtained in the current study. First, the structural model suggested by both Garrison et al. (2010), and Shea and Bidjerano (2009) was handled. Figure 4 reproduced this model.

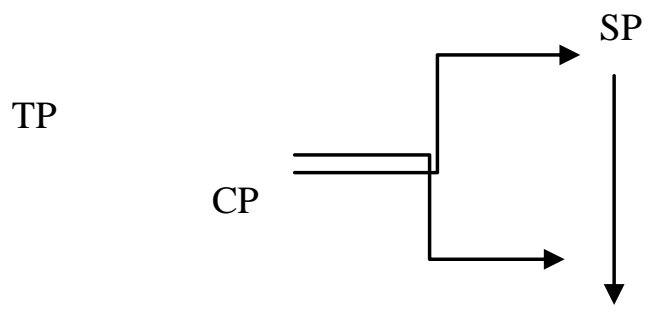

Figure 4. The model with $\mathrm{SP}$ as the partial mediator (Model 4). $\mathrm{TP}=$ Teaching presence. $\mathrm{CP}=\mathrm{Cognitive}$ presence. $\mathrm{SP}=$ Social presence.

A structural equation modeling analysis was run to see whether the model specified in Figure 4 could fit the present data. The resultant model accompanied $t$ values all of which were higher than 3.29 in absolute size thereby being significant at $p<.001$. In other words, the specified relationships were significant as well. The overall model displayed an excellent fit based on GFI $=0.95$, IFI $=0.99, \mathrm{CFI}=$ 0.99 , and NNFI $=0.98$. These are the same values obtained for the hypothesized model of the present investigation. RMSEA was also very similar at a value of 0.077 indicating a reasonable fit again. Consequently, the model with social presence as the partial mediator showed a reasonably very good model given the current data set, $\square^{2}[32, \mathrm{~N}=338, p=.00]=100.31$, which suggested that no further modifications were necessary. A following chi-square difference $\left(\Delta \square^{2}\right)$ test indicated that a difference of 0.42 was not significant at $p=.001$ with a degrees of freedom difference $(\Delta d f)$ of 1 suggesting that both of the models have an equally reasonable very good fit with the present data.

What about further alternate models? Kline (2012) highlighted the importance of recognizing "equivalent" or "near-equivalent" (p. 117) models in structural equation modeling studies. For the rest of this study, some alternate models first were individually examined and then were compared with each other. Even though these alternate models may not be equivalent or near-equaivalent fully, they were examined as potential alternatives. Teaching presence was kept as an exogenous variable in all the following models because Kline (2012) pointed out that especially direct causal relationships depend on certain criteria, including one thing precedes another and a strong rationale based on theory and research. It should be acknowledged here that some of the criteria Kline (2012) presented may not align with the alternate models provided in this paper to their full extent (Please refer to Kline [2012] for all criteria). For example, the criterion that assumes the nonexistence of other possible causes of the relationship between two variables appear to be violated to some extent - in terms of the relationship between teaching presence and social presence — by the first proposed model in the present study since cognitive presence was identified as a full mediator in between.

As for the alternative models examined in this study, a sort of counterbalancing strategy was employed to examine them based on the two models examined here so far. For instance, the final model in this study assumed that cognitive presence would play a full mediator role between teaching presence and social presence. Consequently, a theoretically plausible alternative model that assigned social presence as a full mediator in between teaching presence and cognitive presence was also tested (Figure 5 , next page). 
$\mathrm{TP}$
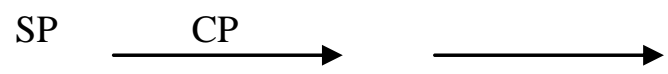

Figure 5. The first alternate model (Model 5): $\mathrm{SP}$ as the full mediator. $\mathrm{TP}=$ Teaching presence $\mathrm{CP}=$ Cognitive presence. $\mathrm{SP}=$ Social presence.

The structural equation modeling analysis examining Model 5 indicated an excellent fit based on $\mathrm{GFI}=0.90, \mathrm{IFI}=0.97, \mathrm{CFI}=0.97$, and NNFI $=0.96$. In contrast, the RMSEA value at 0.12 pointed to a poor fit. All these imply for a somewhat good fit for the model that included social presence as a full mediator between teaching and cognitive presence, $\square^{2}[33, \mathrm{~N}=338, p=.00]=180.90$. This model also resulted in a chi-square value higher than both the model which specified cognitive presence as a full mediator and the model which assigned a partail mediator role to social presence, indicating that the later two may have better fits. Finally, $t$ values for all model specifications were significant at $p<.001$ with absolute magnitudes bigger than 3.29. The next step was to specify the sixth model that includes cognitive presence as a partial mediator instead of social presence. Please note that this is an alternative to the model suggested by Garrison et al. (2010), and Shea and Bidjerano (2009) in which social presence was the partial mediator. Figure 6 displays this model.

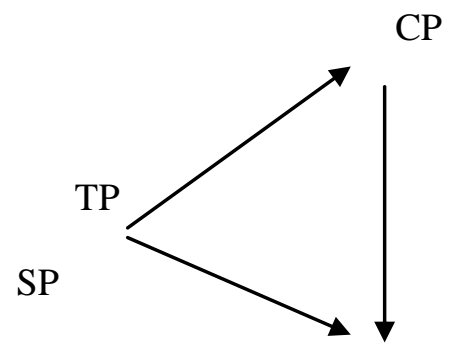

Figure 6. The second alternate model (Model 6): $\mathrm{CP}$ as the partial mediator. $\mathrm{TP}=$ Teaching presence $\mathrm{CP}$ $=$ Cognitive presence. $\mathrm{SP}=$ Social presence.

Results of the structural equation modeling analyses run on Model 6 revealed an excellent fit regarding GFI $=0.95, \mathrm{IFI}=0.99, \mathrm{CFI}=0.99$, and $\mathrm{NNFI}=0.98$. Likewise, the RMSEA value of 0.077 indicated a reasonable fit, $\square^{2}[32, \mathrm{~N}=338, p=.00]=100.31$. All $t$ values pertaining to all model specifications were significant at $p=.001$ except for the $t$ value (-0.66) of the direct link between teaching and social presence (as shown by the arrow going from teaching to social presence in Figure 6 above), which suggested the nonexistence of this link. When we remove the link between teaching and social presence, we are left with the model (e.g., Figure 3) that includes cognitive presence as a full mediator. Consequently, Model 6 in which cognitive presence is a partial mediator did not hold true as a whole.

Despite their theoretical plausibility, Model 4, Model 5 and Model 6 do not align with the results of the bivariate and partial correlation analyses which indicated that cognitive presence may be the full mediator. Similarly, it is still theoretically reasonable to assume that social presence also would directly relate to cognitive presence in the same model. Therefore, one last model, which concurred with both theoretical insights and findings of the correlation analyses, was created (Model 7) in which cognitive presence was assigned the full mediator role while social presence still directly relates to cognitive presence. In other words, Model 7 was non-recursive in that it assumed a reciprocal relationship between cognitive and social presence. Figure 7 (next page) presents this model. 


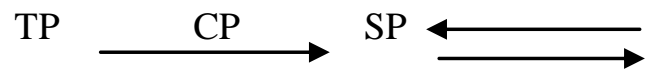

Figure 7. The third alternate model (Model 7): Reciprocal relationship between CP \& SP. $\mathrm{TP}=$ Teaching presence. $\mathrm{CP}=$ Cognitive presence $. \mathrm{SP}=$ Social presence.

The structural equation modeling analysis applied to Model 7 showed an excellent fit based on $\mathrm{GFI}=0.95, \mathrm{IFI}=0.99, \mathrm{CFI}=0.99$, and NNFI $=0.98$. An RMSEA of 0.077 indicated a reasonable fit as well, $\square^{2}[32, \mathrm{~N}=338, p=.00]=100.31$. All $t$ values for all model specifications were significant at $p=$ .001 except for the direct link from social presence to cognitive presence (as shown by the arrow going from social to cognitive presence in Figure 7 above). In other words, the $t$ value (0.70) for this direct link was not significant. This finding suggests that Model 7, which assumes a reciprocal causal relationship between cognitive and social presence, does not hold true as a whole. Interestingly enough, when one moves the nonsignificant direct link of social presence to cognitive presence, what remains is the model (e.g., Figure 3) that specifies cognitive presence as a full mediator. This is exactly what happened to Model 6, where cognitive presence is assumed to be a partial mediator. The failure of these two models as a whole further support the notion of cognitive presence as a full mediator.

In what follows, an overall chi-square difference test was employed to see how Model 3, Model 4, and Model 5 statistically compare with each other. To this end, Table 4 summarizes the relevant structural equation modeling indices obtained in this study, and Table 5 presents the chi-square differences and degrees of freedom differences.

Table 4.

Comparison of structural equation models $(N=338)$

\begin{tabular}{lccccccc}
\hline Model & $\square^{2}$ & $d f$ & RMSEA & GFI & CFI & IFI & NNFI \\
\hline Model 3 & & & & & & & \\
& 100.73 & 33 & 0.076 & 0.95 & 0.99 & 0.99 & 0.98 \\
\hline Model 4 & 100.31 & 32 & 0.077 & 0.95 & 0.99 & 0.99 & 0.98 \\
\hline Model 5 & & & & & & & \\
& 180.90 & 33 & 0.12 & 0.90 & 0.97 & 0.97 & 0.96 \\
\hline
\end{tabular}

Note. Model 6 and Model 7 were not included because they did not hold true as a whole.

Model 3 with cognitive presence as the full mediator.

Model 4 with social presence as the partial mediator.

Model 5 with social presence as the full mediator.

Table 5.

Chi-square $\left(\Delta \square^{2}\right)$ and degrees of freedom differences $(\Delta d f)$

\begin{tabular}{ccc}
$\mathrm{X}-\mathrm{Y}$ & & \\
\hline $3-4$ & 0.42 & 1 \\
\hline $3-5$ & 80.17 & 0 \\
\hline $4-5$ & 80.59 & 1 \\
\hline
\end{tabular}

Note. Model 3 with cognitive presence as the full mediator.

Model 4 with social presence as the partial mediator.

Model 5 with social presence as the full mediator. 
It should be noted here that while calculating the different scores seen in Table 5, the lower scores were subtracted from higher scores, which resulted in positive difference values. These score differences, then, were compared using a chi-square distribution table. Results suggested that Model 3 and Model 4 were not significantly different from each other, even at $p=.25$, indicating that both were equally good models; and Model 4 was significantly different or better than Model 5 with a lower chi-square value at $p$ $=.0005$. Because the degrees of freedom values of Model 3 and Model 5 were equal, it was not possible to compare the two using a chi-square distribution table. However, given that Model 3 and Model 4 have equally good fit with the current data, and that Model 4 has a significantly better fit than Model 5, it is reasonable to assume that Model 3 is at least qualitatively better than Model 5.

Finally, in order to check whether the mediator role of cognitive presence might have emanated from the amount differences among the three presences, a Friedman test was employed. Results of the test indicated a statistical significance among teaching, social and cognitive presence ratings of the participants, $\chi^{2}(2, n=338)=593.215, p<.000$. Median values indicated that there was an increase in participant ratings from social presence $(M d=41.31 ; M=40.21 ; S D=4.30)$ to cognitive presence $(M d=$ 55; $M=54 ; S D=5.60)$ and to teaching presence $(M d=62 ; M=58.86 ; S D=7.03)$. Furthermore, Wilcoxon Signed Ranks Tests showed three statistically significant differences between: (1) teaching presence and cognitive presence, $z=-13.08, p<.001$; (2) teaching presence and social presence, $z=-$ $15.93, p<.001$; and (3) social presence and cognitive presence, $z=-16, p<.001$. Therefore, the results from this study may be bounded according to the statistical differences stated above. Further research may be needed to check for similarities or differences among findings within the context of similar or different statistical differences.

\section{Conclusions}

Kozan and Richardson (2014a) claimed that gaining a better understanding of both correlational and causal relationships between and among teaching presence, social presence, and cognitive presence can significantly enrich our theoretical and practical insights into online learning. The results from this study, which were supported by the results of the bivariate and partial correlation analyses, suggested the possibility of two equally good structural equation models. One of these models was more parsimonious and included cognitive presence as a full mediator between teaching and social presence. This implies that instructors would first focus on increasing the cognitive presence of online learners, which would then increase online learners' social presence. In other words, an increase in online learners' social presence would be a byproduct of efforts by the instructor to increase their cognitive presence.

The model mentioned above (Model 3) was also supported by the failure of two other models, the first of which specified cognitive presence as a partial mediator (Model 6). In this case, the direct link from teaching presence to social presence turned out to be insignificant, indicating that an indirect link between teaching presence and social presence mediated by cognitive presence. The second model (Model 7), which also failed, was a non-recursive model that specified a reciprocal causal relationship between cognitive presence and social presence with cognitive presence as the full mediator between teaching and social presence. The reciprocal relationship between cognitive and social presence in this model did not hold true since the direct link from social presence to cognitive presence was not significant while the direct link from the mediator cognitive presence to social presence was still significant. All of these findings imply that in a structural equation model where cognitive presence initially was given a partial or full mediator role, the resulting model strongly referred to cognitive presence as a full mediator between teaching and social presence.

The second equally good model (Model 4) supported by previous research (e.g. Garrison et al., 2010; Shea \& Bidjerano, 2009) assigned social presence as a partial mediator. This suggested that either 
instructors can increase online learners' cognitive presence directly, and/or they can do so by first increasing their social presence. This means that instructor's efforts to increase online learners' social presence also can increase learners' cognitive presence whether or not instructors focus their efforts directly on increasing learners' cognitive presence. While reading these conclusions, it should be kept in mind that all data were collected towards the end of the semester session when social presence might have already been established. For this reason, further research on structural equation modeling of the three types of presence during different time periods of a semester or semester session are recommended. One alternative would be to collect data at the beginning, middle and end of a semester, which would also provide more valuable insights into the evolution of the relationships between and among teaching, social and cognitive presence during the lifetime of a learning experience. These research efforts would contribute further to the validity of any future results.

This study revealed significant differences between the levels of teaching presence, social presence, and cognitive presence, with teaching presence being the highest and cognitive presence the second highest. The results presented here might be limited to online learning contexts where the level of social presence is the lowest of the three. In other words, there might be online learning contexts where social presence levels would be higher in comparison to cognitive presence, thus identifying social presence as a full mediator as well. One would expect to find this type of context at the very beginning of an online learning experience where learners need to get to know each other before collaboration begins. Results might also differ in face-to-face or blended learning environments where it is easier for learners to engage in real-time interactions. All of these instructional settings warrant future structural equation modeling studies that examine the relationships among the three types of presence, including comparisons of various alternate models and with a focus on differences in the levels of presence within different learning contexts.

This study was also primarily methodological in that it compared different structural equation models.. Consequently, teaching presence, which is assumed to occur earlier in courses, especially in terms of design and organization, was the only exogenous variable assigned. These points suggest that, to some degree, the results presented here might be limited to methodological or theoretical insights. Further research is needed that focuses on the structural equation models of the presence relationships from a more pedagogical or educational perspective in the interest of providing more practical insights. In other words, future models would need to be informed strongly by both methodological and educational implications. Models based more on methodological insights can still provide educational insights even when they do not hold true, as was the case for the model in this study that showed a reciprocal relationship between cognitive and social presence. This was an important finding, as it provided support for the model with cognitive presence as a full mediator, which suggested from an instructional perspective that encouraging cognitive presence may result in higher levels of social presence.

\section{Acknowledgements}

Special thanks go to Dr. Jennifer C. Richardson for letting me use her data for data analysis purposes in this study. I would also like to thank Dr. Chantal Levesque-Bristol for her feedback on an earlier draft of the present paper and participants in this study for their time and contribution. Finally, the two reviewers' productive comments also deserve special thanks.

\section{References}

Akyol, Z., Arbaugh, J. B., Cleveland-Innes, M., Garrison, D. R., Ice, P., Richardson, J.C.., \& Swan, K. (2009). A response to the review of the community of inquiry framework. Journal of Distance Education, 23(2), 123-136.

Kozan, Kadir (2016). A comparative structural equation modeling investigation of the relationships among teaching, cognitive and social presence, Online Learning (20) 3. 
Akyol, Z., \& Garrison, D. R. (2008). The development of a community of inquiry over time in an online course: Understanding the progression and integration of social, cognitive and teaching presence. Journal of Asynchronous Learning Networks, 12(3-4), 3-22.

Anderson, T., Rourke, L., Garrison, D. R., Archer, W. (2001). Assessing teaching presence in a computer conferencing context. Journal of Asynchronous Learning Networks, 5(2), $1-17$.

Arbaugh, B., Cleveland-Innes, M., Diaz, S., Garrison, D. R., Ice, P., Richardson, J.C., \& Swan, K. (2008). Developing a community of inquiry instrument: Testing a measure of the Community of Inquiry Framework using a multi-institutional sample. The Internet and Higher Education, 11(3-4), 133136.

Archibald, D. (2010). Fostering the development of cognitive presence: Initial findings using the community of inquiry survey instrument. The Internet \& Higher Education, 13(1-2), 73-74.

Bollen, K. A., \& Pearl, J. (2013). Eight myths about causality and structural equation models. In S. L. Morgan (Ed.), Handbook of causal analysis for social research (pp. 301-328). Dordrecht: Springer.

Boston, W., Diaz, S. R., Gibson, A. M., Ice, P., Richardson, J., \& Swan, K. (2009). An exploration of the relationship between indicators of the community of inquiry framework and retention in online programs. Journal of Asynchronous Learning Networks, 13(3), 67-83.

Byrne, B. M. (1998). Structural equation modeling with LISREL, PRELIS, and SIMPLIS: Basic concepts, applications and programming. Mahwah, NJ: Lawrence Erlbaum.

Community of Inquiry Survey Instrument. (2014). (draft v14) (d). Retrieved from http://cde.athabascau.ca/coi_site/documents/CoI_survey_Draft_14b.doc

Diaz, S. R., Swan, K., Ice, P., \& Kupczynski, L. (2010). Student ratings of the importance of survey items, multiplicative factor analysis, and the validity of the community of inquiry survey. The Internet and Higher Education, 13, 22-30.

Field, A. (2009). Discovering statistics using SPSS (3rd ed.). London: SAGE Publications.

Garrison, D. R. (2009). Communities of inquiry in online learning. In P. L. Rogers, G. A. Berg, J. V. Boettcher, C. Howard, L. Justice \& K. D. Schenk (Eds.), Encyclopedia of distance learning ( $2^{\text {nd }}$ ed., pp. 352-355). Hershey, PA: IGI Global.

Garrison, D. R. (2011). E-learning in the $21^{\text {st }}$ century: A framework for research and practice $\left(2^{\text {nd }}\right.$ ed.) [Kindle Fire version]. Retrieved from http://www.amazon.com

Garrison, D. R. (2012). Article review - Social presence within the community of inquiry framework. The International Review of Research in Open and Distributed Learning, 13(1), 250-253.

Garrison, D. R., \& Akyol, Z. (2013a). The community of inquiry theoretical framework. In M. G. Moore (Ed.), Handbook of distance education (pp. 104-119). New York, NY: Routledge.

Kozan, Kadir (2016). A comparative structural equation modeling investigation of the relationships among teaching, cognitive and social presence, Online Learning (20) 3. 
Garrison, D. R., \& Akyol, Z. (2013b). Toward the development of a metacognition construct for communities of inquiry. The Internet and Higher Education, 17, 84- 89.

Garrison, D. R., Anderson, T., \& Archer, W. (2000). Critical inquiry in a text-based environment: Computer conferencing in higher education. The Internet and Higher Education, 2(2-3), 87-105.

Garrison, D. R., Anderson, T., \& Archer, W. (2001). Critical thinking, cognitive presence, and computer conferencing in distance education. The American Journal of Distance Education, 15(1), 7-23.

Garrison, D. R., Cleveland-Innes, M., \& Fung, T. S. (2010). Exploring causal relationships among teaching, cognitive and social presence: Student perceptions of the community of inquiry framework. The Internet and Higher Education, 13, 31-36.

Garrison, D. R., \& Arbaugh, J. B. (2007). Researching the community of inquiry framework: Review, issues, and future directions. The Internet and Higher Education, 10(3), 157-172.

Hall, R. J., Snell, A. F., \& Foust, M. S. (1999). Item parceling strategies in SEM: Investigating the subtle effects of unmodeled secondary constructs. Organizational Research Methods, 2(3), 233-256.

Houghton, J. D., \& Jinkerson, D. L. (2007). Constructive thought strategies and job satisfaction: A preliminary examination. Journal of Business Psychology, 22, 45-53.

Jöreskog, K. G., \& Sörbom, D. (2007). LISREL 8.80 for Windows. Skokie, IL: Scientific 398 Software International, Inc.

Ke, F. (2010). Examining online teaching, cognitive, and social presence for adult students. Computers \& Education, 55, 808-820.

Kline, R. B. (2012). Assumptions in structural equation modeling. In R. H. Hoyle (Ed.), Handbook of structural equation modeling (pp. 111-125). New York: The Guilford Press.

Kozan, K. (2016). The incremental predictive validity of teaching, cognitive and social presence on cognitive load. The Internet and Higher Education, 31, 11-19.

Kozan, K., \& Richardson, J.C. (2014a). Interrelationships between and among social, teaching, and cognitive presence. The Internet and Higher Education, 21, 68-73.

Kozan, K., \& Richardson, J.C. (2014b). New exploratory and confirmatory factor analysis insights into the community of inquiry survey. The Internet and Higher Education, 23, 39-47.

Levesque, C., Stanek, L. R., Zuehlke, A. N., \& Ryan, R. M. (2004). Autonomy and competence in German and American university students: A comparative study based on self-determination theory. Journal of Educational Psychology, 96(1), 68-84.

Little, T. D., Cunningham, W. A., \& Shahar, G. (2002). To parcel or not to parcel: Exploring the question, weighing the merits. Structural Equation Modeling, 9(2), 151-173. 
Matthews, D., Bogle, L., Boles, E., Day, S., \& Swan, K. (2013). Developing communities of inquiry in online courses: A design-based approach. In Z. Akyol \& D. R. Garrison (Eds.), Educational communities of inquiry: Theoretical framework, research, and practice (pp. 490-508). Hershey, PA: IGI Global.

Rovai, A. P. (2002). Development of an instrument to measure classroom community. The Internet and Higher Education, 5, 197-211.

Shea, P., \& Bidjerano, T. (2009). Community of inquiry as a theoretical framework to foster "epistemic engagement" and "cognitive presence" in online education. Computers \& Education, 52(3), 543-553.

Shea, P., Hayes, S., Vickers, J., Gozza-Cohen, M., Uzuner, S., Mehta, R., ...Rangan, P. (2010). A re-examination of the community of inquiry framework: Social network and content analysis. The Internet and Higher Education, 13, 10-21. doi:

10.1016/j.iheduc.2009.11.002

Swan, K., Garrison, D. R., Richardson, J.C. (2009). A constructivist approach to online learning: The community of inquiry framework. In C. R. Payne (Ed.), Information technology and constructivism in higher education: Progressive learning frameworks (pp. 43-57). Hershey, PA: IGI Global.

Swan, K., Richardson, J. C., Ice, P., Garrison, D. R., Cleveland-Innes, M., \& Arbaugh, J. B. (2008). Validating a measurement tool of presence in online communities of inquiry. E-mentor, 2(24), 1-12.

Tabachnick, B. G. \& Fidell, L. S. (2013). Using multivariate statistics (6th ed.). Boston: Pearson.

Tomarken, A. J., \& Waller, N. G. (2005). Structural equation modeling: Strengths, limitations, and misconceptions. Annual Review of Clinical Psychology, 1, 31-65. 


\section{Appendix}

Participants were asked to answer the survey questions below by selecting: Strongly disagree Disagree Neutral Agree Strongly agree

1) The instructor clearly communicated important course topics.

2) The instructor clearly communicated important course goals.

3) The instructor provided clear instructions on how to participate in course learning activities.

4) The instructor clearly communicated important due dates/time frames for learning activities.

5) The instructor was helpful in identifying areas of agreement and disagreement on course topics that helped me to learn.

6) The instructor was helpful in guiding the class towards understanding course topics in a way that helped me clarify my thinking.

7) The instructor helped to keep course participants engaged and participating in productive dialogue.

8) The instructor helped keep the course participants on task in a way that helped me to learn.

9) The instructor encouraged course participants to explore new concepts in this course.

10) Instructor actions reinforced the development of a sense of community among course participants.

11) The instructor helped to focus discussion on relevant issues in a way that helped me to learn.

12) The instructor provided feedback that helped me understand my strengths and weaknesses.

13) The instructor provided feedback in a timely fashion.

14) Getting to know other course participants gave me a sense of belonging in the course.

15) I was able to form distinct impressions of some course participants.

16) Online or web-based communication is an excellent medium for social interaction.

17) I felt comfortable conversing through the online medium.

18) I felt comfortable participating in the course discussions.

19) I felt comfortable interacting with other course participants.

20) I felt comfortable disagreeing with other course participants while still maintaining a sense of trust.

21) I felt that my point of view was acknowledged by other course participants.

22) Online discussions helped me to develop a sense of collaboration.

23) Problems posed increased my interest in course issues.

24) Course activities piqued my curiosity.

25) I felt motivated to explore content related questions.

26) I utilized a variety of information sources to explore problems posed in this course.

27) Brainstorming and finding relevant information helped me resolve content related questions.

28) Discussing course content with my classmates was valuable in helping me appreciate different perspectives.

29) Combining new information helped me answer questions raised in course activities.

30) Learning activities helped me construct explanations/solutions.

31) Reflection on course content and discussions helped me understand fundamental concepts in this class.

32) I can describe ways to test and apply the knowledge created in this course.

33) I have developed solutions to course problems that can be applied in practice.

34) I can apply the knowledge created in this course to my work or other non-class related activities. 